Tanıtım / Reviews

\title{
Modern Türk Şiirinde Fransız Etkileri Üzerine Genel Bir Giriş
}

Meliha ÖZHAN*

Kemal Özmen'in Türk edebiyatının Fransız edebiyatı ile ilişkisini ele alan ve Sel Yayıncılık tarafından 2016 yılında yayımlanan Modern Türk Şiirinde Fransız Etkileri ${ }^{1}$ adlı kitabı, Fransız şiiri bağlamında değişim sürecine giren Türk şiirini ayrıntılı biçimde ele alan bir çalışma olarak nitelendirilebilir. Özellikle edebiyatımızın iç dinamiklerini etkilemesi yönüyle önemli bir edebi kaynak kabul edilen Fransız edebiyatı, Tanzimat döneminden itibaren Türk edebiyatının değişimine yön vermeye devam etmektedir. Buna rağmen şiirimizin Fransız kaynaklarıyla ilişkisini inceleyen derinlikli ve bütünlüklü eserlerin ortaya konmamasından ötürü alanda bir boşluk hissedilmektedir. Türk şiirinin gelişiminde ve dönüşümünde Fransız şiirinin oynadığı rolü detaylı bir tahlil ve kavram çalışmasından hareketle ele alan Özmen'in bu kapsamlı eseri söz konusu boşluğu dolduracak niteliktedir.

Yazarın bu kitabı, modern şiirimizin doğuş ve gelişim aşamalarında "kaynak metin" olarak Fransız şiirinin Türk şiirine katkılarını konu aldığı 1999-2016 yılları arasındaki yazılarından oluşmuştur. Kitabın tamamında özellikle "frankofon" şairlerin meydana getirdikleri eserlere, şiirimizin yol haritasının nasıl belirlendiğine, kuramsal düşünce alanındaki kısırlığın süreç içerisinde nasıl aşılmaya çalışıldığına dikkat çekilir (s.11). Özmen'in bu alandaki yazılarının yeniden de-

* İstanbul Medeniyet Üniversitesi, SBE Türk Dili ve Edebiyatı Doktora Öğrencisi, Elmek: melihaozhan@gmail.com

1 Kemal Özmen, Modern Türk Şiirinde Fransız Etkileri, İstanbul: Sel Yayıncılık, 2016. 
ğerlendirmesiyle biçimlenen bu eserde, ekler de dahil olmak üzere on dokuz başlık vardır. Ekler bölümü ise üç başlıktan oluşur ve bu bölümdeki yazılarda; Divan edebiyatımızın iki şairi Sami ve Mahir'in birer şiirinin, İlhan Berk'in “Aragon” adlı eserinin, Ataol Behramoğlu'nun Hayata Uzun Veda adlı kitabındaki şiirlerin, Fransız edebiyatıyla olan metinlerarası ilişkilerinden bahsedilir. Özellikle kitaptaki "Tanzimat Modernizasyonu, 'Frankofoni', Kaynak Kültür ve Etkilenme", "Fransız Etkisinde Modern Türk Şiirinde Yeni Yönelişler Tanzimat Edebiyatında 'Victor Hugo Olayı' ”, “Tevfik Fikret ve Fransız Şiiri (Musset, Coppée): 'Ferdi Bir Melâlden Büyük Bir İnsanlık Ümidine Doğru’”, “Ahmet Haşim’in Sembolizmi:" başlıklı yazılarda tarihsel sürece ve kuramsal tartışmalara da yer verilmekte, dönüşen yeni "sanat algısı"nın arka planı gösterilmeye çalışılmaktadır.

Kitabın "Tanzimat Modernizasyonu, 'Frankofoni Kaynak Kültür ve Etkilenme" ” başlıklı giriş yazısı, "Tanzimat modernizasyonu” ve "frankofoni” kavramlarına odaklanır. "Frankofoni" ilk olarak "Fransa'nın sömürgeleriyle olan dilsel ve kültürel birliğine gönderme yapan bir sömürge kavramı iken" daha sonra "Fransız dilinin, edebiyatının, kültürünün Fransa dışındaki varlığını niteleyen bir kavram" olarak somutlaşmıştır (s.24, 25). "Frankofoni” süreç içinde, "Batı taklitçiliği”, "Batı hayranlı̆̆ı", "dekadan" gibi ifadelerle edebi eserlerde ve çevrelerde eleştiri konusu olsa da Türk edebiyatına çok boyutlu bir açılım ve zihniyet değişimi getirmiştir (s.26). Yazara göre modernist bir dünya görüşüne geçerken kültürel ve düşünsel altyapımız, kuramsal üretimimiz yetersizdir; bu bağlamda yapılan çabalar ise bireysel hamlelerle sınırlıdır. Bu noktada Özmen, Tanzimat döneminde gelişmeye başlayan, kurumsal ve zihinsel düzeyde amaçlanan modernizasyon sürecinin varlığını, ilerleyişin arka planını göstermeye çalışır. Klasik şiire ait birtakım tespitlerden hareketle edebiyatımızın ihtiyaç duyduğu yenileşme sürecinin gerekliliğini açılar ve Tanzimat döneminde keşfedilmeye başlanan Fransız şiirinin Türk şiirine etkisini değerlendirmek için şu konuları tartışmaya açar: Türk edebiyatında eski-yeni tartışmaları, çeviri eserlerin zihniyet değişimine katkıları, Tanzimat dönemindeki yazarların Fransız edebiyatını tanıma süreci, yazarlarımızın romantizm ve realizme olan ilgileri.

Yazının odağındaki bir başka önemli konu ise metinlerarasılıktır. Başkasına ait fikir ya da ifadelerin yeniden kurgulanması ve özgün bir yaratıya 
dönüşmesi mevzusu eskiden beri var olagelen bir sorunsaldır. Özmen'e göre “Fuzuli'nin yaşadığı ve döneminde çözümsüz gibi duran ikilik günümüz metin kuramcıları için artık bir sorun değildir. Başkasına ait olan "fikir" ya da "mazmun” yeni, dahası özgün bir yaratıya dönüşebilir (s.31). Bu bağlamda yazıda, "taklit" eyleminden hareketle yeniden yazım sürecine 1şık tutacak çeşitli görüşlere yer verilir. Taklit, yazarlık deneyiminin oluşması ve edebi bir kimlik oluşturmak için gerekli görülen bir süreçtir. Belirli aşamalarda yazar ve şairlerimizin edebi gelişimi, Fransız kültürü ve edebiyatının etkisinde gerçekleşmiştir, geleneğimizde olmayan türlerin keşfedilmesiyle de edebiyat geleneğimiz genişlemiştir.

Özmen'in “Tevfik Fikret ve Fransız Şiiri (Musset, Coppée): 'Ferdi Bir Melâlden Büyük Bir İnsanlık Ümidine Doğru' ” adlı yazısı Tevfik Fikret'in görüşlerine ve Fransız şairlerinden nasıl etkilendiğine odaklanır. Fikret, Musset'in sanat anlayışından etkilenmiştir ancak şiirlerindeki Musset etkisi, derinliği olmayan bireysel bir içlenme olarak kalmıştır (s.70). Coppée'nin "seçkin bir manzum-nesir" kullanarak şiir yazma üslubunu da taklit etmiş, öykülemeye dayalı biçemle şiire bakış tarzında yeniliklere gitmiştir. Bunun yanı sıra toplumsal içerikli şiirlerinin esin kaynağının ise François Coppée olduğu görülür (s.72). Fikret'in Baudelaire şiirinden aldığı esintiler hakkında yazılan "Paris'ten İstanbul'a Tevfik Fikret'teki Baudelaire Vizyonu” başlıklı yazıda ise; "Ah Ağlasam" adlı şiiri ile Baudelaire'in "Le Balcon" şiiri, "Terennüm" ile "Moesta et Errabunda" şiiri, "Bir Tenezzühten Avdette" ile "Elévation" şiiri, "Bahar-1 mağmum" ile "Recueillement" şiiri, "Zerrişte" ile "Le Chat" şiiri, "Sis" ile "Epilogue" şiiri arasındaki ilişkiler üzerinde durulmuştur. Fikret'in şiiri hem içerik hem de üslup bakımından Baudelaire şiirinden de önemli "etki izleri" taşır. Ancak Özmen'e göre Tevfik' in şiirindeki bu etkiler 'Baudelaire'in dünya görüşü ve şiir estetiğinden kopuk ve uzak bir 'eskiz', bir 'hava', bir 'esinti' görünümündedir” (s.97).

“Ahmet Haşim'in Sembolizmi: Fransız Etkisinde Yeni Bir Şiirsel İdealizm” adlı yazıda, Haşim' in empresyonist ve sembolist üslubu üzerine yapılan tartışmalara yer verilir. Edebiyat çevrelerince yeterince anlaşılmayan ve belirli anlamlara indirgenen bu iki akımın tanımları yapılır, edebi arka planları ayrıntılı 
olarak anlatılır. Bu noktada öncelikle yaygın bir görüş olan "Hâşim sembolist değil, empresyonist bir şairdir" iddiası açımlanır. Özetle şu sonuca varılmıştır: "Oysa bilinmesi gereken temel şey, Hâşim' in sembolist olduğu için "empresyonist" bir dünya ve eşya algısına sahip olduğudur (...) Hiçbir 'sembolist' şair yoktur ki 'empresyonist' olmasın; yani, nesneyi kendi içinde betimlemek, çözümlemek, incelemek yerine, onun doğurduğu izlenimler yoluyla 'tespit etmesin'(...) Mallarmé, Verlaine, Régnier ve diğerleri 'empresyonist' değil midir?” (s.116). Haşim, Fransız sembolist şairlerinden etkilenerek diş dünyadan edindiği izlenimlerle iç dünyasını anlatmıştır. Ancak şiirlerinde yeni duyumlar bulma konusunda sembolistler kadar uzaklara gitmeyi başaramamıştır. "O, bir anlamda, kendi kozası içinde, sembolistlerin düşlediği ‘başkalaşım’ı aklına getirmeden, sınırlı bir sözcük dağarcığı içinde, kendi düşsel/düşünsel/ideal dünyasıyla yetin[miştir]" (s.119).

Özmen'in "Yahya Kemal Şiirinin Fransız Kökenleri Üzerine ya da 'Mektepten Memlekete' " yazısı ise Yahya Kemal'in Fransa'ya gidişini, ulusal aidiyetini ve şiir estetiğini orada nasıl keşfettiğini anlatır. Şair burada; Gautier, Banville, Baudelaire'i, Verlaine'i, Mallarmé'nin şiirlerini keşfeder; bu isimlerin dışında çeşitli Fransız şair ve yazarlarını okur ve etkilenir. "Sorel'in Alman ve İtalyan milliyetlerinin uyanışlarıyla ilgili görüşleri (...) özellikle Maurice Barrés'in milliyetçi söylemleri Yahya Kemal'i Osmanlı Türk tarihini yeni bakışla okumaya isteklendirir" (s.128). Mallarmé'nin şiirinden özellikle "saf şiir, ritim, çağrıştırıcılık ve müzikalite” konusunda etkilenir. Heredia’yı diğer şairlere nispetle geri olarak görse de Latin ve Yunan şairlerinin değerini ondan öğrenir. Şiir tekniği konusunda ise Verlaine şiirleri Yahya Kemal'de en kalıcı etkiyi yapar (s.134). Ancak yazıda bütün bu etkilenmelerin şaire derin bir Batı düşüncesi ve edebiyatı perspektifi sunmadığı gibi, onu "modern dünya"nın yönelişlerine çekmediği vurgulanır. Öte yandan şair Fransız şiirlerinin tesiriyle "kendini”, "tarihini” ve "şiir dili”ni keşfetmeye başlayacaktır. Bu görüşlerin ardından yazıda şöyle bir tespit çıkar karşımıza: "Yahya Kemal' in büyük ölçüde modern Fransız şiirinden hareketle ortaya koyduğu "şiir estetiği”nin özgün bir 'buluş' değil, 19. yüzyıl Fransız sembolist ve parnas şiirinin aşamalı bir 'keşif'i olduğunun altını çizmek gerekir” (s.137). 
“İkoros'un Kavşağında İki Şair: Baudelaire ve Tarancı” başlıklı yazıda ise sanatçılara, şairlere ve yazarlara esin kaynağı olan "İkaros'un düşüşü" mitosu detaylı bir biçimde ele alınır. Biri Fransız, diğeri Türk farklı dönemlerde yaşayan iki şairin yani Baudelaire ve Tarancı'nın birbirine birçok yönüyle benzeyen dramatik hayat serüvenleri, “İkoros'un tutkusu, yükselişi ve düşüşü’ne bağlanarak değerlendirilir. Özmen'in iddiasına göre, Tarancı'nın Baudelaire'in şiirlerinden izler taşıyan şiir ve dize sayısı sanıldığından azdır. "Maziyi ya da Daldığı Zaman" ile "Correspondances" ve "Parfum exotique"; "Uzak Bir İklimde" ile "Correspondances", "Parfum exotique" ve "Harmoni du soir"; "Sarayımız" ve "Düşündüğüm Yer" ile "Invitation au voyage”; “Abbas" ile "Recueullement"; "Ben Aşk Adamııım" ile "Le Rebelle" şiirleri arasında benzerlikler vardır (s.198). Özmen, tespit ettiği bu şiir kesitleri üzerinden Tarancı'nın Baudelaire'den ne ölçüde etkilendiğini tartışmışır. Tartışmanın sonucuna göre Baudelaire etkisindeki Tarancı, Türk şiirine alışılmamış bir hava getirmiş; o döneme kadar işlenmemiş kimi izlekleri şiire sokarak şiirin olanaklarını genişletmiştir. Yazının bir diğer iddiası ise şöyledir: Tarancı'nın şiirlerinde Baudelaire izi, "metinlerarası bir düzlemde ana izleği "sıkıntı" olan ruhsal bir atmosferin yansımalarıdır" (s.232).

Özmen'in “Tanpınar'ın Şiirindeki Bergson ya da 'Bugünün Işs̆ğında Maziyi Görmek Keyfiyeti’ ” yazısında zaman kavrayışını bireysel, toplumsal ve kültürel olgular boyutunda ilk kez işleyen kişinin Tanpınar olduğu dile getirilir. Tanpınar'ın Bergson'u tanıma ve eserlerinde Bergsoncu süreyi ele alma süreci anlatılarak seçilen şiirler üzerinden "süre"nin varlığı açıklanır. Tanpınar zamanı çizgisel ve ölçülebilir kategorilerle ele almaktan öte Bergsoncu anlamda tüm zamansal kategorilerin içselleştirilmiş alg1 ve anılarla iç içe geçtiği varoluşsal bir oluşum olarak ele almıştır (s.235).

“Tanpınar'ın Valéry Rüyası” yazısında ise Tanpınar'ın şiirinde rüya imajı çeşitli yönleriyle ve detaylı biçimde değerlendirilmiştir. Şiirlerinde Valéry gibi güçlü bir soyutlama yapmaya çalışmışsa da Tanpınar bunu "rüya hali" içine sıkıştırmış, yer yer yapaylığa ve özentili, süslü bir anlatıma düşmüştür (s. 282). Onun şiirinin özünde yer alan "rüya" imajında; dünyayı, eşyayı, zamanı, insanı, olguları algılama biçimi ortaya çıkar ve bir tür aşkınlık vardır. Öte yandan 
bilinçli bir kurgu olan rüyası otantik değildir, bir tür yazınsal süstür. Valery'nin rüya algısı gibi "alt bir bilinç düzeyi modeli"nden farklıdır, bununla birlikte Tanpınar'ın rüya algısının Nerval'in yorumlarıyla örtüşen yönleri de vardır (s.283, 285).

"Orhan Veli'nin Fransızcadan Şiir Çevirileri ya da 'Kendi Şiirini Yazmak" " başlıklı yazıda ise Türk edebiyatındaki başarılı şiir çeviri örneklerine ve edebiyatımıza olan etkilerine dikkat çekilir; bunun yanı sıra Orhan Veli'nin şiir çeviri faaliyetlerine ve etkilenme sürecine yer verilir. Orhan Veli Fransızca'dan otuz beş şiir çevirmiş, başka dillerden hikâye, şiir ve roman çevirileri de yapmıştır. Bu çeviri metinleri Özmen, “çeviri yoluyla bir değişim köprüsü kurmak” biçiminde nitelendirir. Yaptığı bu çeviriler, aynı zamanda şairin kendi orijinal şiirlerini yazmasına vesile olmuş; şiir estetiğini olgunlaştırmış ve şiirsel yaratıcılığını beslemiştir (s.315).

"Metinlerarasılı̆̆ın Kıyısında Bir Şair: Ahmet Muhip Dıranas" adlı yazıda, Dıranas'ın şiirindeki metinlerarasılık ve şiir estetiği ele alınır. Özellikle şiir ya da dize düzeyinde en çok etkilendiği şairin Baudelaire olduğu ifade edilir. Ancak Dıranas, bazı şiirlerinde bu etkilenmeyi yeterince özümsememiş, bazılarında ise yeni bir kurgu ile başarılı metinler ortaya çıkarmıştır. Yazıda Dıranas'ın belirli şiirlerinden örneklere de yer verilmiş ve bu şiirlerdeki metinlerarasıllk çeşitli yönleriyle tartışılmıştır. Tüm bu saptamaların ardından Özmen, Fransız şiirinin Dıranas'ın şiirine belirli bir çokseslilik niteliği kazandırmakla beraber, bu etkinin yeni bağlam içinde tam olarak şiirsel dile dönüşemediğini belirtmiştir (s.334).

“İhan Berk’teki Fransız Şiiri ya da 'Bir Başkası Ama Yine de Kendisi' " adlı yazıda, Berk'in Fransız şiiriyle karşılaşması ve poetikasını oluştururken nasıl bir sistematiği temel aldığı tartışılır. Özmen'e göre Berk; Apollinare, Rimbaud ve Mallarme'nin şiir anlayışlarından yararlanmıştır. Bunun yanı sıra Pound, Eliot, Cummings gibi anglo-sakson şairlerden gelen etkiler daha başat bir gelenek olarak Berk’te yankı bulmuştur (s.338). Öte yandan Paris dönüşüyle birlikte Osmanlı şiirinin geleneksel kaynaklarına da yaslanmıştır. Bu yazıda Özmen, bir şairin bu kadar etkiden sonra özgün olup olamayacağı fikrini tart1şır. Tartışmanın sonucunda, yer yer içerdiği öykünmeci yanlarına karşın İlhan 
Berk'in şiir dilinin modernist açılımlara örnek oluşturması açısından özgün olduğunu söyler (s.356.)

Özmen'in bu çalışması; Tevfik Fikret, Ahmet Haşim, Yahya Kemal, Cahit Sitk1 Taranc1, Orhan Veli, Ahmet Hamdi Tanpınar, Ahmet Muhip Diranas, İlhan Berk gibi Fransız şiiriyle bağlantılı şairlerin, şiir estetiklerine ve metinlerarası yaklaşımlarına odaklanırken; farklı bakış açılarını ve kuramsal arka planı kapsamlı bir biçimde vermesiyle dikkat çekicidir. Modern şiirimizin gelişim aşamalarını da inceleyen bu yazılarda, öne çıkan medeniyet merkezli değişim ve etkileşim sürecinde "özgünlük" bağlamının yeniden gözden geçirilmesi, metinlerdeki etkileşimi ve bağlantıları daha anlaşılır kılmıştır. Ayrıca, Özmen'in şairlerimizin Fransız şiirleriyle ilişkisini verilerle ve metin odaklı çözümlemeleri dikkate alarak eleştirel bir üslupla incelemiş olması, buna bağlı olarak sanat algılarını tekrar irdelemesi, belirsiz ve yanlış anlaşılan birçok konuyu farklı yönleriyle tekrar düşünmeyi mümkün k1lmıştır. Sonuç olarak, Tanzimat döneminden itibaren başlayan modernleşme olgusunu ve Fransız edebiyatının Türk şiirini nasıl etkilediğini çarpıcı tespitler ve derin analizlerle ortaya koyan bu eser, alanda yapılacak başka okumalara da imkân sunabilecek ve yol gösterecek düzeydedir. 